\title{
Bilateral Acute Osteoporotic Lumbar Pedicle Fracture Presenting with Associated Neurological Deficit: A Case Report and Review of Literature
}

\author{
James Ebot ${ }^{1}$, Angela M. Bohnen ${ }^{1}$, Kingsley Abode-Iyamah ${ }^{1}$ \\ 1. Neurosurgery, Mayo Clinic, Jacksonville, USA
}

Corresponding author: James Ebot, jebot80@gmail.com

\begin{abstract}
Osteoporosis is a common cause of vertebral compression fractures. Often times affecting post-menopausal women, these fractures may occur spontaneously or following minor trauma and are typically managed nonsurgically. Here we present a case of a 67-year-old patient who presented with acute compression fracture of the lumbar 5 vertebra and bilateral pedicle fractures of the fourth and fifth lumbar vertebrae following an episode of coughing secondary to tracheitis. She underwent a lumbar 3 to sacral 1/ilium instrumentation/arthrodesis, with screw augmentation via hydroxyapatite, followed by lumbar $4 / 5$ laminectomy and foraminotomy.
\end{abstract}

Categories: Neurosurgery

Keywords: pedicle fracture, compression fracture, radiculopathy, post-menopausal, osteoporosis

\section{Introduction}

Osteoporosis is a common cause of vertebral compression fractures. Often times affecting post-menopausal women, these fractures may occur spontaneously or following minor trauma, and are typically managed non-surgically [1]. Bilateral pedicle fracture of the vertebrae is uncommon and is especially rare without trauma or high velocity activity. Even more uncommon is neurologic deficit following these fractures [2]. Here we present a case of a 67-year-old patient who presented with acute osteoporotic compression fracture of the lumbar 5 vertebra and bilateral pedicle fractures of the fourth and fifth lumbar vertebrae following an episode of coughing secondary to tracheitis.

\section{Case Presentation}

A 67-year-old female, with a history of untreated osteopenia for five years, presented to an outside emergency department with acute back pain. Her symptoms began after an episode of severe coughing related to a recently diagnosed tracheitis. She was diagnosed with a lumbar 5 compression fracture, at an outside hospital, and was managed non-surgically with medication. She subsequently presented, after one

Received 02/13/2020 Review began 02/20/2020 Review ended 03/11/2020 Published 03/14/2020

(c) Copyright 2020 Ebot et al. This is an open access article distributed under the terms of the Creative Commons Attribution License CC-BY 4.0., which permits unrestricted use, distribution, and reproduction in any medium, provided the original author and source are credited. month, to our emergency room with three days of new onset bilateral lumbar 5 radicular leg pain and dorsiflexion weakness.

Physical examination revealed axial back pain with weight bearing movement and pain to percussion in the lower lumbar spine. Neurologically she demonstrated decreased sensation in the right lumbar 5 dermatome and 5/5 strength in all lower extremity muscle groups except her bilateral dorsiflexion, which was $3 / 5$. Her body mass index was 21 .

CT scan of the lumbar spine revealed a lumbar 5 compression fracture as well as bilateral pedicle fractures at L4 and L5 (Figure 1). An MRI of the lumbar spine demonstrated bilateral, lateral recess stenosis causing compression of the bilateral lumbar 5 nerve roots (Figure 2). 


\section{Cureus}

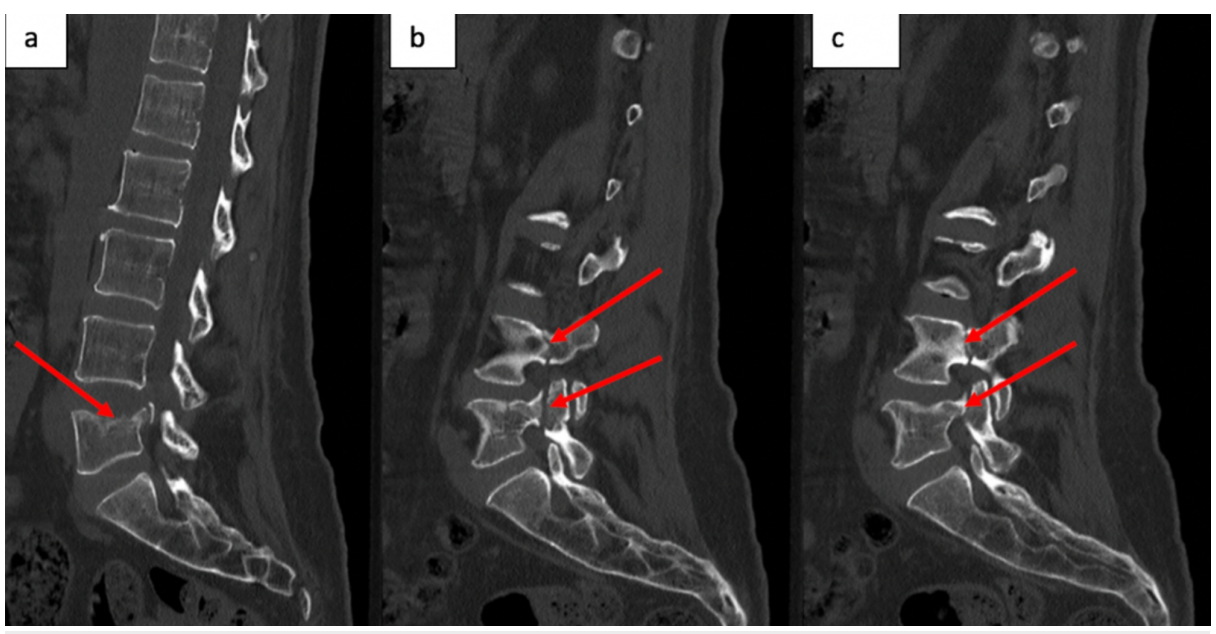

\section{FIGURE 1: CT of the spine}

Non-contrast CT lumbar spine of a midline sagittal cut, which demonstrates the lumbar 5 compression fracture with retropulsed superior posterior fragment (a). Lateral sagittal images demonstrating left and right pedicle fractures at lumbar 4 and lumbar 5 (b and $c)$.

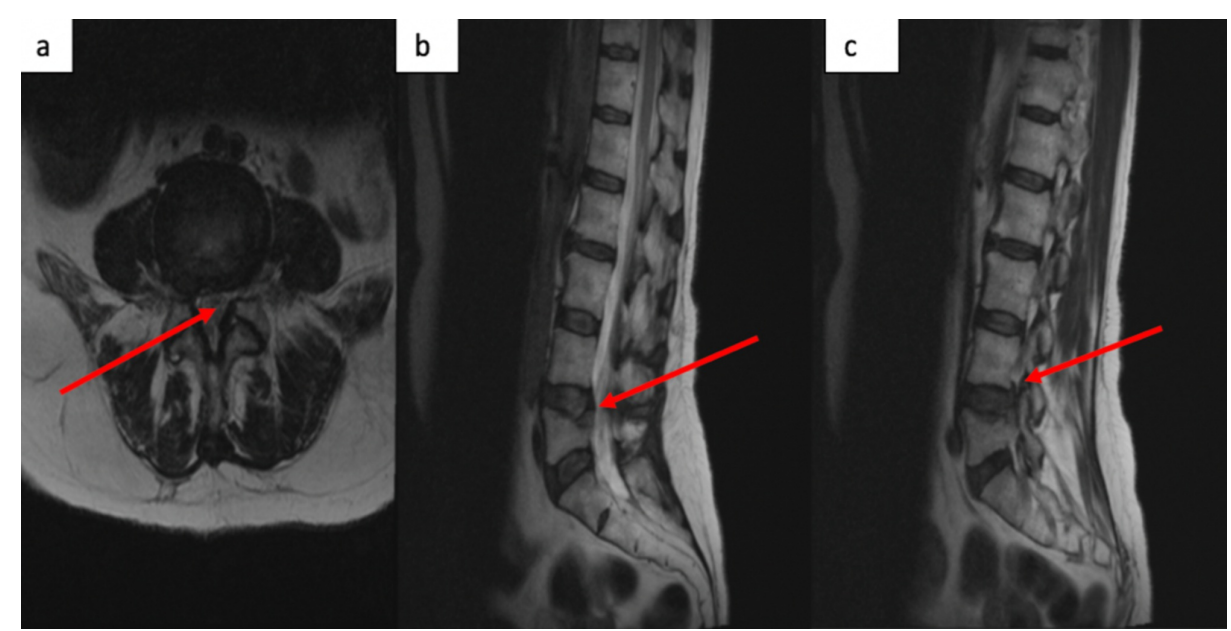

\section{FIGURE 2: MRI of the spine}

T2-weighted, non-contrast MRI lumbar spine revealing central stenosis at the L4/5 level in the sagittal (b) and axial (a) views with significant thecal sac compression with severe stenosis of the traversing L5 nerve

root. The lateral, sagittal view identifies moderate $L 4 / 5$ foraminal stenosis with impingement on the $L 4$ exiting nerve root (c).

Given the severity of the patient's progressive pain and neurological deterioration, surgical intervention was discussed. She subsequently underwent a lumbar 3 to sacral 1/ilium instrumentation/arthrodesis, with screw augmentation via hydroxyapatite, followed by lumbar 4/5 laminectomy and foraminotomy (Figure 3).

Intraoperative neuro-monitoring was without initial deficit or procedural changes. Postoperatively, the patient's preoperative axial back pain significantly improved and her dorsiflexion strength improved to $5 / 5$. The patient was subsequently discharged to rehab on day 5 . On her subsequent postoperative visits, she remained pain free with $5 / 5$ strength in her dorsiflexion. 


\section{Cureus}

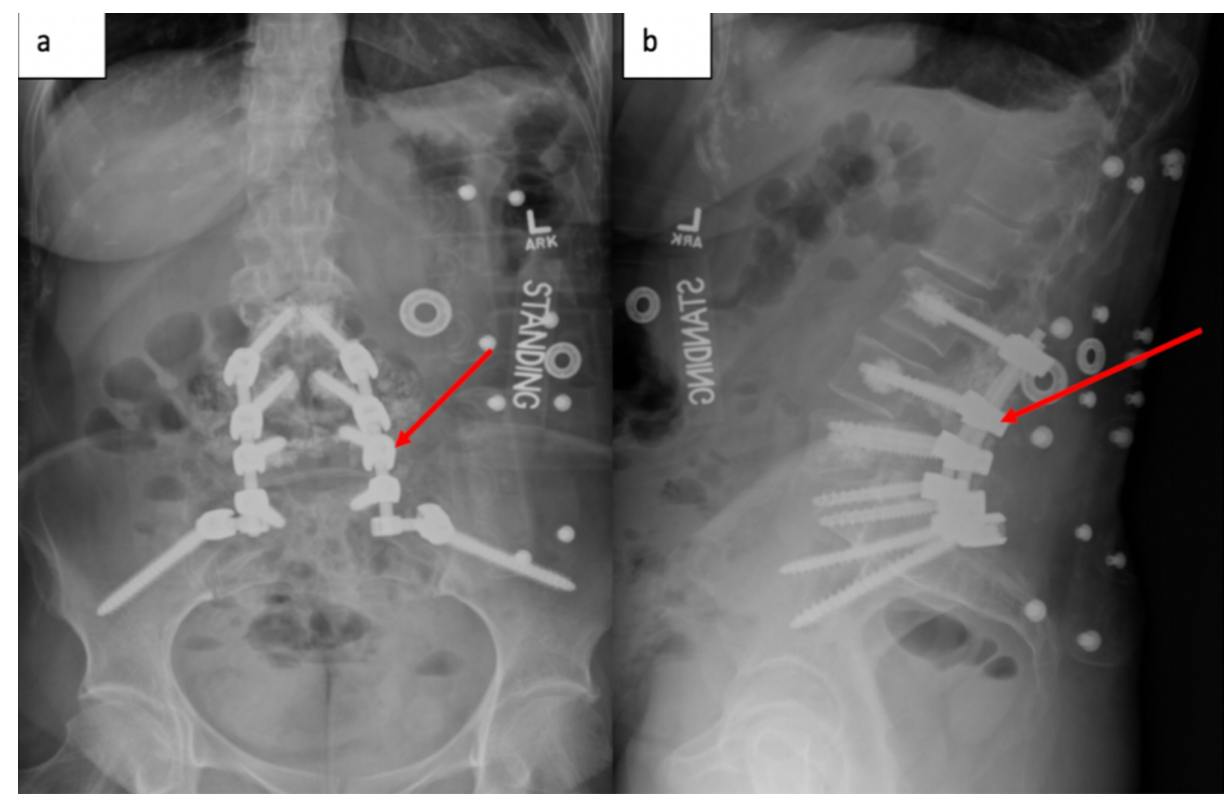

\section{FIGURE 3: Plane films of the spine}

Postoperative AP (a) and sagittal (b) X-rays demonstrate the L3-S1/pelvis instrumentation.

Standing - Patient is in the standing position.

\section{Discussion}

As Americans age, the risk of osteoporotic fractures increases, along with their social and economic impact. It is estimated that $50 \%$ of the population 50 years and greater are at high risk for osteoporosis. Osteoporotic fractures are suspected to total more than 3 million by 2025 , an increase of $48 \%$, surpassing a national burden of $\$ 25$ billion dollars in 2025 with a cumulative 10 -year burden of $\$ 228$ billion [3].

Vertebral body compression fractures are a frequent cause of neurosurgical consultation in the elderly population, particularly post-menopausal women $[4,5]$. The most common presenting symptom is pain. Occasionally, patients complain of subjective weakness secondary to limited mobility and pain, but without objective findings. Most fractures can be treated non-surgically including pain medication, modification of activity and bracing [4]. For patients in whom mobilization is limited due to severe pain, even after bracing, a vertebroplasty or balloon kyphoplasty can be considered [5]. Surgical intervention is reserved for patients with continued fracture collapse, instability, and neural compromise.

Compression of neural elements, causing radiculopathy due to an osteoporotic compression fracture is rare [6]. Even more unlikely is the presentation of bilateral pedicle fractures in association with an osteoporotic vertebral body compression fracture [2]. Our patient had osteopenia, placing her at risk for compression fractures related to minor trauma. Her tracheitis and frequent episodes of violent coughing spells were the likely inciting event of her fractures, as her pain started immediately after a forceful episode. Our patient is unique given her fracture pattern and need for surgical intervention due to progressive neurological deterioration. In addition, our case highlights that attention to bone health and aggressive treatment of osteopenia/osteoporosis are important to prevent such fractures and minimize the morbidity that may follow.

We performed a thorough PubMed search for non-traumatic bilateral pedicle fractures. Thirteen previous reports were identified [2, 6-17] (Table 1). All patients presented with either low back pain, leg pain, or both. There were 10 females and three males, showing a female predominance. Six patients were managed conservatively and seven patients were managed surgically. Age did not seem to influence whether conservative versus surgical management was pursued. Four of the 13 patients had a known diagnosis of osteoporosis, all were females aged 50 and above. 


\section{Cureus}

\begin{tabular}{|c|c|c|c|c|c|c|c|c|}
\hline Reference & Age & Sex & Fracture & Level & Symptom & Activity / Risk Factor & Osteoporosis & Treatment \\
\hline Doita et al., 2009 & 77 & $\mathrm{~F}$ & $\begin{array}{l}\text { Bilateral } \\
\text { pedicle }\end{array}$ & L4 & LBP & $\begin{array}{l}\text { Prior L5 Compression } \\
\text { fracture }\end{array}$ & + & Surgical \\
\hline Chung et al., 2002 & 67 & $\mathrm{~F}$ & $\begin{array}{l}\text { Bilateral } \\
\text { pedicle }\end{array}$ & L4 & LP & None & + & Conservative \\
\hline Kim et al., 2019 & 60 & $\mathrm{~F}$ & $\begin{array}{l}\text { Bilateral } \\
\text { pedicle }\end{array}$ & L2-4 & LBP \& LP & $\begin{array}{l}\text { Unilateral L4/5 } \\
\text { spondylosis }\end{array}$ & - & Surgical \\
\hline Schmid et al., 2017 & 57 & M & $\begin{array}{l}\text { Bilateral } \\
\text { pedicle }\end{array}$ & L4 & LBP \& LP & Lumbar stenosis L2-5 & Unknown & Surgical \\
\hline $\begin{array}{l}\text { Traughber and Havlina, } \\
1991\end{array}$ & 16 & $\mathrm{~F}$ & $\begin{array}{l}\text { Bilateral } \\
\text { pedicle }\end{array}$ & L5 & LBP & Unknown & - & Conservative \\
\hline Amari et al., 2009 & 14 & $\mathrm{M}$ & $\begin{array}{l}\text { Bilateral } \\
\text { pedicle }\end{array}$ & L4 & LBP \& LP & Ballet dancer & - & Conservative \\
\hline Parvataneni et al., 2004 & 19 & $\mathrm{~F}$ & $\begin{array}{l}\text { Bilateral } \\
\text { pedicle }\end{array}$ & L5 & LBP & College lacrosse & - & Surgical \\
\hline Sadiq, 2006 & 36 & $\mathrm{~F}$ & $\begin{array}{l}\text { Bilateral } \\
\text { pedicle }\end{array}$ & L2 & LBP & Sedentary & - & Conservative \\
\hline Hajjioui et al., 2011 & 54 & $\mathrm{~F}$ & $\begin{array}{l}\text { Bilateral } \\
\text { pedicle }\end{array}$ & L4 & LBP & Unknown & + & Conservative \\
\hline Ireland and Micheli, 1987 & 18 & $\mathrm{~F}$ & $\begin{array}{l}\text { Bilateral } \\
\text { pedicle }\end{array}$ & L2 & LBP & Ballet dancer & - & Conservative \\
\hline $\mathrm{Ha}$ and Kim, 2003 & 50 & $\mathrm{~F}$ & $\begin{array}{l}\text { Bilateral } \\
\text { pedicle }\end{array}$ & L5 & LBP \& LP & Unknown & - & Surgical \\
\hline $\begin{array}{l}\text { Johnson and Wang, } \\
2009\end{array}$ & 50 & $\mathrm{~F}$ & $\begin{array}{l}\text { Bilateral } \\
\text { pedicle }\end{array}$ & L4 & LBP \& LP & Sedentary & + & Surgical \\
\hline Doita et al., 2008 & 57 & M & $\begin{array}{l}\text { Bilateral } \\
\text { pedicle }\end{array}$ & L4 & LBP \& LP & Unknown & Unknown & Surgical \\
\hline
\end{tabular}

TABLE 1: Published literature identifying non-traumatic patients presenting with bilateral pedicle fractures

LBP: Low back pain; LP: Leg pain; +: Positive; -: Negative; M: Male; F: Female.

Osteoporotic patients with fragility fractures require a multi-disciplinary workup, including neurosurgery, internal medicine and endocrinology. Bence Jones proteins were obtained to rule out multiple myeloma while further imaging was used to rule out the presence of any primary or metastatic spine malignancy. Once it was determined her fractures were a result of poor bone health, a decision was made to offer surgery with the goal of decompressing her neural elements and stabilizing her spine.

Minorities of postmenopausal women undergo bone health workup after an initial fragility fracture and about $50 \%$ of patients with known osteoporosis defer pharmacological treatment. Furthermore, data suggests a gap in patient education and knowledge regarding osteoporosis and bone health to be, at least, related to under-treatment [3]. Such information begs for surveillance protocols and national standards on diagnosis and treatment.

New guidelines for the diagnosis and treatment of osteoporotic fractures in post-menopausal women were published in 2019 by the International Osteoporosis Foundation (IOF) and the European Society for Clinical and Economic Evaluation of Osteoporosis and Osteoarthritis (ESCEO), aiding in algorithmic treatment of patients with increased fracture risk [18]. Practitioners should be well versed in both preventative and rebuilding factors. Anabolic treatment of osteoporosis has significant advantage in prevention of fracture risk compared to anti-resorptive medications, and plays a significant role in a subset of osteoporotic patients [19].

Post-surgically, our patient was sent to the bone health clinic for further workup and 
treatment. Unfortunately, as she only demonstrated osteopenia, she did not qualify for anabolic medication. Routine exercise, medication, supplementation, and surveillance will be important factors in her ongoing spine-health.

\section{Conclusions}

We have described the unique fracture pattern and clinical presentation of a non-traumatic osteopeniarelated fracture. Osteopenia/osteoporosis fractures are frequent occurrences; however, they mainly involve the vertebral body alone. Compression fractures in association with bilateral pedicle fractures are extremely rare. Moreover, neural compromise without progression of fracture is unexpected. Our case highlights the importance of heightening one's suspicion for hidden pathology based on a patient's nonstandard presentation. In addition, we stress the importance of a thorough, multidisciplinary approach and treatment strategy of both the fracture and underlying etiology, to maximize diagnosis and minimize comorbidity associated with the treatment of such patients.

\section{Additional Information \\ Disclosures}

Human subjects: Consent was obtained by all participants in this study. Conflicts of interest: In compliance with the ICMJE uniform disclosure form, all authors declare the following: Payment/services info: All authors have declared that no financial support was received from any organization for the submitted work. Financial relationships: All authors have declared that they have no financial relationships at present or within the previous three years with any organizations that might have an interest in the submitted work. Other relationships: All authors have declared that there are no other relationships or activities that could appear to have influenced the submitted work.

\section{References}

1. Ferreira ML, March L: Vertebral fragility fractures - How to treat them? . Best Pract Res Clin Rheumatol. 2019, 33:227-235. 10.1016/j.berh.2019.03.017

2. Doita M, Ando Y, Hirata S, Ishikawa H, Kurosaka M: Bilateral pedicle stress fracture in a patient with osteoporotic compression fracture. Eur Spine J. 2009, 18:206-209. 10.1007/s00586-008-0816-5

3. Lewiecki EM, Leader D, Weiss R, Williams SA: Challenges in osteoporosis awareness and management: results from a survey of US postmenopausal women. J Drug Assess. 2019, 8:25-31. 10.1080/21556660.2019.1579728

4. McCarthy J, Davis A: Diagnosis and management of vertebral compression fractures . Am Fam Physician. 2016, 94:44-50.

5. Luthman S, Widen J, Borgstrom F: Appropriateness criteria for treatment of osteoporotic vertebral compression fractures. Osteoporos Int. 2018, 29:793-804. 10.1007/s00198-017-4348-x

6. Chung SK, Lee SH, Kim DY, Lee HY: Treatment of lower lumbar radiculopathy caused by osteoporotic compression fracture: the role of vertebroplasty. J Spinal Disord Tech. 2002, 15:461-468. 10.1097/00024720200212000-00005

7. Traughber PD, Havlina JM Jr: Bilateral pedicle stress fractures: SPECT and CT features . J Comput Assist Tomogr. 1991, 15:338-340. 10.1097/00004728-199103000-00033

8. Schmid T, Heini P, Benneker L: A rare case of non-traumatic, multi-level, bilateral pedicle fractures of the lumbar spine in a 60-year-old patient. Eur Spine J. 2017, 26:197-201. 10.1007/s00586-017-5029-3

9. Sadiq MZ: Bilateral pedicle stress fracture in the lumbar spine of a sedentary office worker . Eur Spine J. 2006, 15:653-655. 10.1007/s00586-006-0184-y

10. Parvataneni HK, Nicholas SJ, McCance SE: Bilateral pedicle stress fractures in a female athlete: case report and review of the literature. Spine (Phila Pa 1976). 2004, 29:19-21. 10.1097/01.BRS.0000105988.43472.2B

11. Kim K, Isu T, Morimoto D, Kokubo R, Iwamoto N, Morita A: Incidental idiopathic bilateral pedicle fracture Case report and literature review. NMC Case Rep J. 2019, 6:35-37. 10.2176/nmccrj.cr.2018-0185

12. Johnson JN, Wang MY: Stress fracture of the lumbar pedicle bilaterally: surgical repair using a percutaneous minimally invasive technique. J Neurosurg Spine. 2009, 11:724-728. 10.3171/2009.7.SPINE08373

13. Ireland ML, Micheli LJ: Bilateral stress fracture of the lumbar pedicles in a ballet dancer. A case report . I Bone Joint Surg Am. 1987, 69:140-142.

14. Hajjioui A, Khazzani H, Sbihi S, Bahiri R, Benchekroune B, Hajjaj-Hassouni N: Spondylolisthesis on bilateral pedicle stress fracture in the lumbar spine: a case study. (Article in English, French). Ann Phys Rehabil Med. 2011, 54:53-58. 10.1016/j.rehab.2010.12.001

15. Ha KY, Kim YH: Bilateral pedicle stress fracture after instrumented posterolateral lumbar fusion: a case report. Spine (Phila Pa 1976). 2003, 28:158-160.

16. Doita M, Shimomura T, Nishida K, Maeno K, Fujioka H, Kurosaka M: Bilateral pedicle stress fracture in a patient with lumbar spinal stenosis: a case report. J Spinal Disord Tech. 2008, 21:531-534. 10.1097/BSD.0b013e31815b7e05

17. Amari R, Sakai T, Katoh S, Sairyo K, Higashino K, Tachibana K, Yasui N: Fresh stress fractures of lumbar pedicles in an adolescent male ballet dancer: case report and literature review. Arch Orthop Trauma Surg. 2009, 129:397-401. 10.1007/s00402-008-0685-8

18. Kanis JA, Cooper C, Rizzoli R, Reginster JY, Scientific Advisory Board of the European Society for Clinical and Economic Aspects of Osteoporosis and Osteoarthritis (ESCEO) and the Committees of Scientific Advisors and National Societies of the International Osteoporosis Foundation (IOF): Executive summary of the European guidance for the diagnosis and management of osteoporosis in postmenopausal women. Calcif Tissue Int. 2019, 104:235-238. 10.1007/s00223-018-00512-x 


\section{Cureus}

19. Kendler DL, Marin F, Zerbini CAF, et al.: Effects of teriparatide and risedronate on new fractures in postmenopausal women with severe osteoporosis (VERO): a multicentre, double-blind, double-dummy, randomised controlled trial. Lancet. 2018, 391:230-240. 10.1016/S0140-6736(17)32137-2 